\title{
Cardiac and arrhythmic complications in Covid-19 patients.
}

\author{
Adriano Nunes Kochi et al. ${ }^{1}$ \\ ${ }^{1}$ Affiliation not available
}

April 28, 2020

\begin{abstract}
In December 2019, the world started to face a new pandemic situation, the severe acute respiratory syndrome coronavirus 2 (SARS-CoV-2). Although COVID-19 clinical manifestations are mainly respiratory, major cardiac complications are being reported. Cardiac manifestations etiology seems to be multifactorial, comprising direct viral myocardial damage, hypoxia, hypotension, enhanced inflammatory status, ACE2-receptors downregulation, drug toxicity, endogenous catecholamine adrenergic status, among others. Studies evaluating COVID-19 patients presenting cardiac injury markers show that it is associated with poorer outcomes, and arrhythmic events are not uncommon. Besides, drugs currently used to treat the COVID-19 are known to prolong the QT interval and can have a proarrhythmic propensity. This review focus on COVID-19 cardiac and arrhythmic manifestations and, in parallel, makes an appraisal of other virus epidemics as SARS-CoV, MERS-CoV, and H1N1 influenza.

Published in the Journal of Cardiovascular Electrophysiology. DOI forthcoming.

\section{Full author list}

Adriano Nunes Kochi MD MSc ${ }^{1}$, Ana Paula Tagliari MD MSc${ }^{2}$, Giovanni Battista Forleo MD PhD ${ }^{3}$, Gaetano Michele Fassini $\mathrm{MD}^{1}$, Claudio Tondo $\mathrm{MD} \mathrm{PhD}^{1,4}$.

${ }^{1}$ Heart Rhythm Center at Centro Cardiologico Monzino IRCCS, Milan - Italy.

${ }^{2}$ Cardiovascular Surgery Department. University Hospital of Zurich

${ }^{3}$ Azienda Ospedaliera-Universitaria Luigi Sacco, Milan - Italy

${ }^{4}$ Dept. of Clinical Sciences and Community Health at University of Milan. Milan - Italy.
\end{abstract}

\section{Abbreviations}

ATP: antitachycardia pacing

CO: cardiac output

CRT-D: cardiac resynchronization therapy defibrillator

CHF: congestive heart failure

COVID-19: coronavirus disease-2019

CK: creatine kinase

HF: heart failure

HR: hazard ratio

hs-cTnI: high-sensitivity cardiac troponin I 
HCQ: hydroxychloroquine

ICD: implantable cardiac defibrillator

ICU: intensive care unit

LVEF: left ventricular ejection fraction

MERS-CoV: Middle East respiratory syndrome-coronavirus

ND: not disclosed

NHC: National Health Commission of China

OR: odds ratio

RBBB: right bundle branch block

Rev: reversible

SARS: severe acute respiratory syndrome

SARS-CoV: severe acute respiratory syndrome-coronavirus

SARS-CoV-2: severe acute respiratory syndrome-coronavirus 2

SCD: sudden cardiac death

SVT: supraventricular tachycardia

TnT: troponin $\mathrm{T}$

VA: ventricular arrhythmias

VF: ventricular fibrillation

VT: ventricular tachycardia

\section{Introduction}

Since the last December, the entire world is facing a new pandemic situation, the severe acute respiratory syndrome coronavirus 2 (SARS-CoV-2). After emerging from Wuhan-China, the coronavirus disease-2019 (COVID-19) quickly spread throughout the world. Due to all its unknown factors, physicians are passing through real-time learning process. As the disease spreads, a massive wave of information takes over scientific journals and media.

This new virus belongs to the same severe acute respiratory syndrome-coronavirus (SARS-CoV) and Middle East respiratory syndrome-coronavirus (MERS-CoV) family. Although COVID-19 clinical manifestations are mainly respiratory, with the growing number of infected patients, major cardiac complications have been reported in a considerable number of COVID-19 patients ${ }^{1-3}$.

SARS-CoV-2 infection is associated with a variety of pro-inflammatory mediators that may play important roles in the pathophysiology of cardiac and arrhythmic complications. In a single center study ${ }^{1}$ cardiac injury was observed in 19\% of hospitalized patients with COVID-19, and it was associated with higher risk of in-hospital mortality. Therefore, it is plausible that these patients have an even higher risk of cardiac arrhythmias.

Aiming to shed some light in this issue, we performed this review focused on COVID-19 cardiac manifestations not only by analyzing the preliminary available evidence about the virus, but also by making comparative considerations with SARS-CoV, MERS-CoV and H1N1 influenza.

\section{Lesson from previous epidemics}


Much of our present knowledge of SARS-CoV-2 comes from previous historical epidemics that preceded the current outbreak, as SARS-CoV, MERS-CoV, and H1N1 influenza syndromes. It was observed, during these outbreaks, a significant association between underlying cardiovascular disease, myocardial injury, and worse outcomes ${ }^{4}$.

The first human infection by a new strain of coronavirus, the SARS-CoV, was reported in 2002. At that time it was known that, at least in rabbits, coronavirus infections could induce cardiomyopathy resulting in cardiac chambers dilatation and systolic function impairment, simulating other dilated cardiomyopathies ${ }^{5}$.

In humans, hypotension, cardiac arrhythmias, and even sudden cardiac death were described as possible SARS-CoV manifestations ${ }^{6}$. In a cohort of 121 patients, Yu CM et al. demonstrated that sinus tachycardia was the commonest cardiovascular SARS-CoV finding with an overall incidence of $72 \%$. Persistent tachycardia mean duration was 12.7 days with a mean heart rate of 117 beats/min (range: 102-150 beats/min) and the tachycardia remained persistent in nearly $40 \%$ of patients within 30 days after hospital discharge. The incidence of tachycardia during the third hospitalization week, when most patients were afebrile, could be related to drug treatment, such corticosteroid and ribavirin. However, corticosteroid therapy was not associated with persistent tachycardia during follow-up. Hence, longstanding tachycardia could eventually be due to autonomic tone changing. Or, alternatively, sinus tachycardia secondary to cardiopulmonary or peripheral deconditioning since this disease resulted in prolonged bed rest ${ }^{7}$.

Besides these findings, significant sinus bradycardia was seen in 18 (14.9\%) patients. Unlike tachycardia, which was persistent, bradycardia was somewhat transient with a mean heart rate of 43 beats/min (range: $38-49$ beats $/ \mathrm{min}$ ) and a mean duration of 2.6 days. Reversible cardiomegaly was also reported in 13 (10.7\%), with no clinical evidence of heart failure. Transient atrial fibrillation was observed in one patient ${ }^{7}$.

Lau ST et al. additionally described that palpitation, in the form of tachycardia at rest or mild exertion, was noted amongst patients recovering from SARS. Possible causes, according to them, were deconditioning, impaired pulmonary function, impaired cardiac function, cardiac arrhythmia, thyroid dysfunction, anemia, autonomic dysfunction, and anxiety state ${ }^{8}$.

Trying to explain the occurrence of cardiac arrest in 15 SARS patients, Pan SF et al. suggested some possible mechanisms: (1) lung injury caused by SARS virus leading to hypoxemia and an unsteady state in myocardial electricity; (2) SARS direct causing new myocardial cells and/or conduction system damage; (3) SARS infection aggravating pre-existing myocardial conditions, or conduction disturbances; (4) extreme anxiety leading to further endogenous catecholamine release, causing myocardial electrical instability (see figure 1$)^{9}$.

In the setting of the 2012 MERS-CoV syndrome, despite some similarities with SARS-CoV, the early mortality rate for the former achieved $60 \%^{10}$, remaining higher than $35 \%$ during the overall outbreak period, while for SARS-CoV the mortality rate was about $10 \%^{11}$. A meta-analysis suggested that MERS-CoV infection was more likely to occur in patients with underlying cardiovascular diseases ${ }^{12}$. In terms of overall complications, renal failure $(40.9 \%)$, cardiac arrhythmias $(15.7 \%)$, hepatic dysfunction $(31.4 \%)^{13}$, besides pericarditis, and hypotension were the most commonly reported ${ }^{14}$. In a case report published by Alhogbani, he describes an acute myocarditis caused by MERS-CoV; a 60-year-old presenting with respiratory symptoms, chest pain, and persistent tachycardia (120bpm). Echocardiogram demonstrated severe LV function impairment, cardiac magnetic resonance showed typical findings of acute myocarditis, and sputum was positive for MERS-CoV. The patient was intubated and required hemodialysis, after 6 weeks of ICU and 1 month of ward hospitalization, he was discharged in stable condition ${ }^{15}$.

Last but not least, influenza virus infection is well-known to aggravate a plenty of cardiovascular disorders, being associated with myocarditis, myocardial infarction, and heart failure exacerbation ${ }^{16}$.

An interesting survey conducted by Madjid M et al. tested the possible effect of seasonal influenza on the occurrence of ventricular arrhythmias (VA) requiring shock or antitachycardia pacing (ATP) treatment in patients with implantable cardiac defibrillator (ICD) or cardiac resynchronization therapy defibrillator 
(CRT-D). The results indicated that more shocks were delivered during influenza season than during other periods of the year, suggesting a correlation between higher arrhythmia burden and influenza season. The multivariate generalized linear model showed that during high influenza activity, patients were more likely to have a VA treated with shock [odds ratio (OR) 1.06; $p<0.001$ ] or ATP $(\text { OR } 1.06 ; p<0.0001)^{17}$.

Multiple mechanisms have been proposed to explain influenza triggering arrhythmias, among them severe systemic, arterial, and myocardial inflammatory reaction seems to be one of the most plausible. Moreover, influenza is known to exacerbate congestive heart failure (CHF) and increase CHF-related hospital admissions ${ }^{18}$. Decompensated CHF, besides leading to hospitalization, is related to electrical myocardial homeostasis impairment, causing VTs treated with shock or ATP therapy. In patients with underlying ischemic cardiomyopathy, the worsening of ischemia by increased oxygen demand and potential acute coronary syndromes led by influenza can also have a role in the increase of arrhythmic events ${ }^{17}$.

These concepts were strengthened by a nationwide Denmark studied, which showed a strong relationship between yearly influenza vaccination and mortality in heart failure patients. In this study, annual influenza vaccination was associated with $18 \%$ reduction in the adjusted risk of all-cause death and $18 \%$ reduction in the adjusted risk of cardiovascular death $(p<0.001$, for both). Remarkably, those who received more than one seasonal vaccination also had a more pronounced reduction in atrial fibrillation incidence [hazard ratio (HR) $0.94 ; p=0.009]$. According to this study, influenza infection may result in increased metabolic demand, hypoxia, and adrenergic surges, which may lead to acute decompensation or exacerbation of heart failure. Additionally, the infection may induce a hypercoagulable state and trigger acute coronary syndromes, resulting in further left ventricular function deterioration, or it could cause direct myocardial depression. Based on these results, the authors advocated that influenza vaccination may be a valuable treatment strategy to improve survival in heart failure patients ${ }^{19}$.

\section{COVID-19}

Despite not being particularly lethal, SARS-CoV-2 is very contagious. In a published clinical cohort of COVID-19 patients, they observed that acute cardiac injury, shock, and arrhythmias were present in $7.2 \%$, $8.7 \%$, and $16.7 \%$ of patients, respectively, with higher prevalence amongst patients requiring intensive care ${ }^{2}$. In this report, myocardial injury biomarkers levels were significantly higher in patients requiring intensive care unit (ICU) admission than in those not treated in the ICU [median creatine kinase (CK)-MB level $18 \mathrm{U} / \mathrm{l}$ vs. $14 \mathrm{U} / \mathrm{l} ; p<0.001$; and high-sensitivity cardiac troponin I (hs-cTnI) level $11.0 \mathrm{pg} / \mathrm{ml}$ vs. 5.1 $\mathrm{pg} / \mathrm{ml} ; p=0.004]$, suggesting that patients with severe symptoms often have complications involving acute myocardial injury ${ }^{2}$. Overall, arrhythmia rate was also more frequent in ICU patients $(44.4 \%$ vs. $6.9 \% ; p<$ 0.001). Despite the relevance of these initial data, the authors did not provide any arrhythmia classification or definition.

A study from Shi et al. evaluated a single-center cohort of 416 patients hospitalized due to COVID-19. He observed that cardiac lesion, defined by hs-cTnI $>99^{\text {th }}$ percentile of on admission, was present in $19.7 \%$, with median value of $0.19(0.08-1.12) \mu \mathrm{g} / \mathrm{L}$ in this group. Compared with those without cardiac injury, patients with cardiac injury required more noninvasive ventilation $(46.3 \%$ vs. $3.9 \% ; p<0.001)$ and invasive mechanical ventilation $(22.0 \%$ vs. $4.2 \% ; p<0.001)$, and also had a higher mortality $(51.2 \%$ vs. $4.5 \%$; $\mathrm{p}<0.001)$. It's remarkable that the elevated troponin group was older and significantly more ill, but after adjustment for all the possible confounding factors, still the cardiac injury was a predictor of mortality (HR $4.2695 \%$ CI 1.92-9.49) ${ }^{1}$.

In another small report, Huang $\mathrm{C}$ et al. demonstrated that SARS-CoV-2 associated myocardial injury occurred on 5 out of 41 patients, and was manifested as an increase in hs-cTnI levels $(>28 \mathrm{pg} / \mathrm{ml})$. Among these 5 patients, ICU management was required in 4 , indicating the severe nature of the myocardial injury in patients with COVID- $19^{20}$.

In a study by Guo et al., 187 SARS-CoV-2 positive patients were analyzed, stratified by the level of troponin, which was elevated in 27.8\%. During hospitalization, patients with elevated troponin T (TnT) levels developed more frequently complications as acute respiratory distress syndrome (57.7\% vs. $11.9 \%)$, malignant 
ventricular arrhythmias (11.5\% vs. $5.2 \%$ ), acute coagulopathy (65.8\% vs. $20.0 \%)$, and acute kidney injury ( $36.8 \%$ vs. $4.7 \%$ ), compared with those with normal TnT levels. But the most impressive observation is that mortality was markedly higher in patients with elevated plasma TnT levels than in patients with normal TnT levels $(59.6 \% \text { vs. } 8.9 \%)^{21}$.

Contrary to the above mentioned studies Zhou et al. comparing survivors and non-survivors in a cohort of 191 patients from 2 hospitals in Wuhan, found that, despite more frequent in non survivors (46\% vs. $1 \%$, $\mathrm{p}<0.001$ ), hs-cTnI $>28 \mathrm{pg} / \mathrm{ml}$ was not associated with mortality in multivariate analysis. Even though, it is remarkable that this study was unpowered to draw conclusions from this analysis due to the excess of variable for only 54 events $^{22}$.

Acute myocarditis, as well as ventricular arrhythmias might represent the first clinical manifestation of SARS-CoV-2 infection ${ }^{3,44}$. In the epicenter of the current Italian epidemic, sudden cardiac death (SCD) likely occurred in many non-hospitalized patients with mild symptoms who were found dead home while in quarantine. Myocardial biomarkers should be evaluated in all COVID-19 patients for risk stratification and prompt intervention. Even after hospital discharge, we should consider that myocardial injury might result in atrial or ventricular fibrosis, the substrate for subsequent cardiac arrhythmias. The extent of myocardial scar, as assessed with cardiac magnetic resonance, might be a powerful tool to better stratify the arrhythmic risk in patients recovered from COVID-19 who had evidence of myocardial injury at the time of infection.

Another relevant aspect of COVID-19 infection is that early diagnosis can be confounded in patients with chronic cardiac conditions, once the most frequent symptoms, like fatigue (51\%, 95\% CI 34-68\%), dyspnea $(30 \%, 95 \%$ CI $21-40 \%)$ and cough $(67 \%, 95 \% \text { CI } 59-76 \%)^{25}$ can also be manifestations of decompensated heart failure or arrhythmic syndrome. Corroborating with this concern, the National Health Commission of China (NHC) reported that among SARS-CoV-2 infection confirmed cases, cardiovascular symptoms were the first presentation in some patients. The problem behind these atypical presentations is that patients suffering from heart palpitations and chest tightness rather than respiratory symptoms, such as fever and cough, had a delayed COVID-19 diagnosis ${ }^{26}$. Still according to the NHC, among the people who died from COVID-19, 11.8\% had substantial heart damage, with elevated troponin I levels or cardiac arrest during hospitalization $^{26}$.

Explanatory theories regarding COVID-19 cardiovascular affection postulate that chronic cardiovascular diseases may become unstable in the setting of a viral infection as a consequence of the imbalance between the infection-induced increase in metabolic demand and reduced cardiac reserve ${ }^{2}$. This imbalance, concurrent with an accentuated inflammatory response and myocardial damage, could raise the risk of acute coronary syndromes, heart failure, and arrhythmias.

The deleterious SARS-CoV-2 infection myocardial effects could also be perpetuated by the prompt and severe down-regulation of myocardial and pulmonary ACE2 pathways, thereby mediating myocardial inflammation, lung edema, and acute respiratory failure ${ }^{27}$. ACE2 is widely expressed not only in the lungs but also in the cardiovascular system and, therefore, ACE2-related signaling pathways might even have a role in heart injury. Other proposed mechanisms of myocardial injury include a cytokine storm triggered by an imbalanced response by type 1 and type 2 T-helper cells ${ }^{20,28}$, strong interferon-mediated immunopathological events ${ }^{29}$, and respiratory dysfunction and hypoxemia caused by COVID-19, resulting in damage to myocardial cells. Therapeutic use of corticosteroids, in this context, would further augment the possibility of adverse cardiovascular events.

Regarding hypoxemia caused by COVID-19, it is relevant to highlight that this condition can trigger atrial fibrillation, which is the most common arrhythmia among elderly individuals, and that atrial fibrillation can become persistent even before pulmonary improvement. Furthermore, the systemic inflammatory response would make anticoagulation therapy for atrial fibrillation very complex ${ }^{30}$.

\section{Chloroquine and hydroxychloroquine side effects on cardiovascular system}

Another essential aspect to be discussed is about chloroquine cardiovascular side effects since this is one 
of the promising drugs that have been tested in COVID-19 patients. It is well-reported that long-term chloroquine use may increase depolarization length duration and Purkinje fiber $\backslash$ souts refractory period ${ }^{31-34}$, ultimately leading to atrioventricular nodal and/or His system malfunction ${ }^{31}$.

As an antimalarial drug, both chloroquine and hydroxychloroquine (HCQ) are accumulated in lysosomes, directly inhibiting phospholipase activity, inducing cytoplasmic inclusion body formation, increasing lysosomal $\mathrm{pH}$ and causing protein inactivity ${ }^{31,35}$. Due to these properties, drug-induced atrial and ventricular arrhythmias have been associated with their use ${ }^{31-35}$. The most usual electrocardiographic alteration is fascicular block, which can lead to advanced types of atrioventricular block, generally associated with syncope ${ }^{36}$.

HCQ can also induce QT interval prolongation, an extremely rare but potential fatal side effect, due to the risk of induced polymorphic ventricular tachycardia and SCD. The proposed mechanism by which HCQ causes QT interval prolongation is not well understood. In 2015, Capel et al. demonstrated, in guinea pig sinoatrial node myocytes, an inhibitory effect of the HCQ on the hyperpolarization-activated current ion channels (also known as "funny current" channels), along with delayed rectifier potassium currents, and L-type calcium ion currents $^{37}$. Inhibitory effects on pacemaker cells were shown to cause delayed rates in depolarization leading to decreased heart rates. These findings may correlate with a proposed mechanism by which refractory action potentials in cardiac myocytes may lead to prolongation of QT interval due to delayed depolarization and repolarization from abnormal ion currents ${ }^{38}$. QT prolongation in individual medical therapy is not always predictable, dose adjustments and/or additional monitoring of electrocardiograms may be appropriate in some cases. HCQ proarrhythmic risk must be monitored in patients with underlying cardiovascular or renal disorders, and high caution should be posed in the case of electrolyte imbalance, dysrhythmias or concurrent use of QTc-prolonging drugs ${ }^{38}$.

\section{Conclusion}

Acute lung injury is a common problem in COVID-19 patients and results in significant morbidity and mortality. However, increasing clinical and epidemiological evidence suggests that COVID-19 infection is associated with myocardial injury and arrhythmic complications.

Even though the prevalence of COVID-19 arrhythmogenic has yet not been reported, close cardiovascular surveillance is advisable, particularly in patients with more severe presentation and in those with increased baseline risk due to previous cardiac comorbidities. Since many medications are being used empirically to treat the infection and/or symptoms, there is a need to increase awareness to possible drug interactions and close monitoring in atrioventricular conduction and QT interval.

\section{References}

1. Shi S, Qin M, Shen B, et al. Association of Cardiac Injury With Mortality in Hospitalized Patients With COVID-19 in Wuhan, China. JAMA 2020 Mar 25 $5^{\text {th }}$, online first publication. DOI: 10.1001/jamacardio.2020.0950.

2. Wang D, Hu B, Hu C, et al. Clinical Characteristics of 138 Hospitalized Patients With 2019 Novel Coronavirus-Infected Pneumonia in Wuhan, China. JAMA 2020 Feb $7^{\text {th }}$, online first. DOI: 10.1001/jama.2020.1585.

3. Hu H, Ma F, Wei X, Fang Y. Coronavirus fulminant myocarditis saved with glucocorticoid and human immunoglobulin. Eur Heart J 2020 Mar $16^{\text {th }}$ online first publication. DOI: 10.1093/eurheartj/ehaa190.

4. Sellers SA, Hagan RS, Hayden FG, Fischer WA $2^{\text {nd }}$. The hidden burden of influenza: A review of the extra-pulmonary complications of influenza infection. Influenza Other Respir Viruses 2017;11:372393.

5. Alexander LK, Small JD, Edwards S, Baric RS. An experimental model for dilated cardiomyopathy after rabbit coronavirus infection. J Infect Dis 1992;166:978-85.

6. Xiong TY, Redwood S, Prendergast B, Chen M. Coronaviruses and the cardiovascular system: acute and longterm implications. Eur Heart J 2020 Mar 18 ${ }^{\text {th }}$, online first publication. DOI: 10.1093/eurheartj/ehaa231.

7. Yu CM, Wong RS, Wu EB, et al. Cardiovascular complications of severe acute respiratory syndrome. Postgrad Med J 2006;82:140-4. 
8. Lau ST, Yu WC, Mok NS, Tsui PT, Tong WL, Cheng SW. Tachycardia amongst subjects recovering from severe acute respiratory syndrome (SARS). Int J Cardiol 2005;100:167-9.

9. Pan SF, Zhang HY, Li CS, Wang C. Cardiac arrest in severe acute respiratory syndrome: analysis of 15 cases. Zhonghua Jie He He Hu Xi Za Zhi. 2003;26:602-5.

10. Centers for Disease Control and Prevention (CDC). Update: Severe respiratory illness associated with Middle East Respiratory Syndrome Coronavirus (MERS-CoV)-worldwide, 2012-2013. MMWR Morb Mortal Wkly Rep 2013;62:480-3.

11. Maslow JN. Vaccines for emerging infectious diseases: Lessons from MERS coronavirus and Zika virus. Hum Vaccin Immunother. 2017;13:2918-2930.

12. Badawi A, Ryoo SG. Prevalence of comorbidities in the Middle East respiratory syndrome coronavirus (MERS-CoV): a systematic review and meta-analysis. Int J Infect Dis 2016;49:129-33.

13. Saad M, Omrani AS, Baig K, et al. Clinical aspects and outcomes of 70 patients with Middle East respiratory syndrome coronavirus infection: a single-center experience in Saudi Arabia. Int J Infect Dis 2014;29:301-6.

14. Al-Abdallat MM, Payne DC, Alqasrawi S, et al. Hospital-associated outbreak of Middle East respiratory syndrome coronavirus: a serologic, epidemiologic, and clinical description. Clin Infect Dis 2014;59:1225-33.

15. Alhogbani T. Acute myocarditis associated with novel Middle east respiratory syndrome coronavirus. Ann Saudi Med. 2016;36:78-80.

16. Nguyen JL, Yang W, Ito K, Matte TD, Shaman J, Kinney PL. Seasonal Influenza Infections and Cardiovascular Disease Mortality. AMA Cardiol 2016;1:274-81.

17. Madjid M, Connolly AT, Nabutovsky Y, Safavi-Naeini P, Razavi M, Miller CC. Effect of High Influenza Activity on Risk of Ventricular Arrhythmias Requiring Therapy in Patients With Implantable Cardiac Defibrillators and Cardiac Resynchronization Therapy Defibrillators. Am J Cardiol 2019;124:4450 .

18. Ang LW, Yap J, Lee V, et al. Influenza-Associated Hospitalizations for Cardiovascular Diseases in the Tropics. Am J Epidemiol 2017;186:202-209.

19. Modin D, Jorgensen ME, Gislason G, et al. Influenza Vaccine in Heart Failure. Circulation. 2019;139:575586.

20. Huang C, Wang Y, Li X, et al. Clinical features of patients infected with 2019 novel coronavirus in Wuhan, China. Lancet 2020;395:497-506.

21. Guo T, Fan Y, Chen M, et al. Cardiovascular Implications of Fatal Outcomes of Patients With Coronavirus Disease 2019 (COVID-19). JAMA Cardiol 2020 Mar $27^{\text {th }}$, online first publication DOI: 10.1001/jamacardio.2020.1017.

22. Zhou F, Yu T, Du R, et al. Clinical course and risk factors for mortality of adult inpatients with COVID-19 in Wuhan, China: a retrospective cohort study. Lancet 2020;395:1054-1062.

23. Li SS, Cheng $\mathrm{C}, \mathrm{Fu} \mathrm{C}$, et al. Left ventricular performance in patients with severe acute respiratory syndrome: a 30-day echocardiographic follow-up study. Circulation 2003;108:1798-803.

24. Harris JE, Shah PJ, Korimilli V, Win H. Frequency of troponin elevations in patients with influenza infection during the 2017-2018 influenza season. Int J Cardiol Heart Vasc 2019;22:145-147.

25. Yang J, Zheng Y, Gou X, et al. Prevalence of comorbidities in the novel Wuhan coronavirus (COVID19) infection: a systematic review and meta-analysis. Int $\mathrm{J}$ Infect Dis $2020 \mathrm{Mar} 12^{\text {th }}$, online first publication. DOI: 10.1016/j.ijid.2020.03.017.

26. Zheng YY, Ma YT, Zhang JY, Xie X. COVID-19 and the cardiovascular system. Nat Rev Cardiol. $2020 \mathrm{Mar} 5^{\text {th }}$, online first publication. DOI: $10.1038 / \mathrm{s} 41569-020-0360-5$.

27. Oudit GY, Kassiri Z, Jiang C, et al. SARS-coronavirus modulation of myocardial ACE2 expression and inflammation in patients with SAR. Eur J Clin Invest 2009;39:618-25.

28. Wong CK, Lam CW, Wu AK, et al . Plasma inflammatory cytokines and chemokines in severe acute respiratory syndrome. Clin Exp Immunol 2004;136:95-103.

29. Cameron MJ, Bermejo-Martin JF, Danesh A, Muller MP, Kelvin DJ. Human immunopathogenesis of severe acute respiratory syndrome (SARS). Virus Res. 2008;133:13-9. 
30. Yang C, Jin Z. An Acute Respiratory Infection Runs Into the Most Common Noncommunicable Epidemic - COVID-19 and Cardiovascular Diseases. JAMA Cardiol 2020 March 25 $5^{\text {th }}$, online first publication. DOI:10.1001/jamacardio.2020.0934.

31. Ratliff NB, Estes ML, McMahon JT, Myles JL. Chloroquine-induced cardiomyopathy. Arch Pathol Lab Med 1988;112:578.

32. Seshadri MS, John L, Varkey K, Koshy TS. Ventricular tachycardia in a patient on dehydroemetine and chloroquine for amoebic liver abscess. Med J Aust 1979;1:406-7.

33. Fauchier JP, Fauchier L, Babuty D, Breuillac JC, Cosnay P, Rouesnel P. Drug-induced ventricular tachycardia. Arch Mal Coeur Vaiss 1993;86:757-67.

34. Siqueira-Batista R, Ramos Junior AN, Pessanha BS, Sforza-de-Almeida MP, Potsch DF. Chloroquine and cardiac arrhythmia: case report. East Afr Med J 1998;75:117-9.

35. Harris L, Downar E, Shaikh NA, Chen T. Antiarrhythmic potential of chloroquine: new use for an old drug. Can J Cardiolo 1988;4:295-300.

36. Verny C, de Gennes C, Sebastien P, et al. Heart conduction disorders in long-term treatment with chloroquine: two new cases. Presse Med 1992;2:800-4.

37. Capel RA, Herring N, Kalla M, et al. Hydroxychloroquine reduces heart rate by modulating the hyperpolarization-activated current If: Novel electrophysiological insights and therapeutic potential. Heart Rhythm 2015;12:2186-94.

38. O'Laughlin JP, Mehta PH, Wong BC. Life Threatening Severe QTc Prolongation in Patient with Systemic Lupus Erythematosus due to Hydroxychloroquine. Case Rep Cardiol 2016;2016:4626279.

39. Lee $\mathrm{N}$, Hui $\mathrm{D}, \mathrm{Wu} \mathrm{A}$, et al. A major outbreak of severe acute respiratory syndrome in Hong Kong. N Engl J Med 2003;348:1986-94.

40. Booth CM, Matukas LM, Tomlinson GA, et al. Clinical features and short-term outcomes of 144 patients with SARS in the greater Toronto area. JAMA 2003;289:2801-9.

41. Al-Tawfiq JA, Hinedi K, Ghandour J, et al. Middle East respiratory syndrome coronavirus: a casecontrol study of hospitalized patients. Clin Infect Dis 2014;59:160-5.

42. Schoen K, Horvat N, Guerreiro NFC, de Castro I, de Giassi KS. Spectrum of clinical and radiographic findings in patients with diagnosis of $\mathrm{H} 1 \mathrm{~N} 1$ and correlation with clinical severity. BMC Infect Dis 2019;19:964.

43. Assiri A, Al-Tawfiq JA, Al-Rabeeah AA, et al. Epidemiological, demographic, and clinical characteristics of 47 cases of Middle East respiratory syndrome coronavirus disease from Saudi Arabia: a descriptive study. Lancet Infect Dis 2013;13:752-61.

44. Inciardi RM, Lupi L, Zaccone G, et al. Cardiac Involvement in a Patient With Coronavirus Disease 2019 (COVID-19). JAMA Cardiol 2020 Mar 27 $7^{\text {th }}$, online first publication. DOI: $10.1001 /$ jamacardio.2020.1096.

Table 1. Cohorts that evaluated cardiac manifestations in SARS-CoV, MERS-CoV, H1N1, and SARS-CoV2

\begin{tabular}{llllll}
\hline & $\begin{array}{l}\text { First author } \\
\text { (year) }\end{array}$ & $\begin{array}{l}\text { Number of } \\
\text { patients }\end{array}$ & $\begin{array}{l}\text { Cardiac } \\
\text { Manifestations }\end{array}$ & Troponin & $\begin{array}{l}\text { In-Hospital } \\
\text { Mortality }\end{array}$ \\
\hline SARS-CoV & Lee $(2003){ }^{39}$ & 138 & $\begin{array}{l}\text { Acute HF } \\
(1 \mathrm{pt})\end{array}$ & None & $3.6 \%$ \\
& Booth $(2003))^{40}$ & 144 & $\begin{array}{l}\text { Pulse>100bpm } \\
(46 \%) \text { Chest } \\
\text { pain }(10.4 \%)\end{array}$ & ND & $6.5 \%$
\end{tabular}




\begin{tabular}{|c|c|c|c|c|c|}
\hline & $\begin{array}{l}\text { First author } \\
\text { (year) }\end{array}$ & $\begin{array}{l}\text { Number of } \\
\text { patients }\end{array}$ & $\begin{array}{l}\text { Cardiac } \\
\text { Manifestations }\end{array}$ & Troponin & $\begin{array}{l}\text { In-Hospital } \\
\text { Mortality }\end{array}$ \\
\hline & $\mathrm{Li}(2003)^{23}$ & 46 & $\begin{array}{l}\text { RBBB 15.2\% } \\
\text { LVEF-HF 1pt } \\
\text { (EF 30.2\%) } \\
\text { Initial TTE } \\
\text { compare with } 30 \\
\text { days control: } \\
\text { Lower LVEF } \\
\text { Lower } \\
\text { Doppler-derived } \\
\text { CO }\end{array}$ & ND & $13 \%$ \\
\hline & $\mathrm{Yu}(2003)^{7}$ & 121 & $\begin{array}{l}\text { Tachycardia } \\
(71.9 \%) \\
\text { Hypotension } \\
(50.4 \%) \\
\text { Bradycardia } \\
(14.9 \%) \text { Rev } \\
\text { cardiomegaly } \\
(10.7 \%)\end{array}$ & ND & ND \\
\hline \multirow[t]{4}{*}{ MERS-CoV } & Saad (2014) ${ }^{13}$ & 70 & $\begin{array}{l}\text { Arrythmias } \\
(15.7 \%)\end{array}$ & ND & $60 \%$ \\
\hline & $\underset{41}{\text { Al-Tawfiq (2014) }}$ & 17 & $\begin{array}{l}\text { X-ray } \\
\text { cardiomegaly } \\
(53 \%) \text { Chest } \\
\text { pain }(7 \%)\end{array}$ & ND & $76 \%$ \\
\hline & $\begin{array}{l}\text { Assiri (2016) } \\
43\end{array}$ & 47 & $\begin{array}{l}\text { Chest pain } \\
(15 \%)\end{array}$ & ND & $60 \%$ \\
\hline & $\begin{array}{l}\text { Al-Albdallat } \\
(2014)^{14}\end{array}$ & 9 & $\begin{array}{l}\text { Chest pain } \\
(44 \%) \\
\text { Pericarditis (1 } \\
\text { pt) VT (1 pt) } \\
\text { SVT (1 pt) }\end{array}$ & ND & $22 \%$ \\
\hline \multirow{4}{*}{$\begin{array}{l}\text { H1N1 } \\
\text { Influenza } \\
\text { SARS-CoV-2 }\end{array}$} & $\begin{array}{l}\text { Schoen (2019) } \\
42\end{array}$ & 160 & $\begin{array}{l}\text { Chest pain } \\
(5 \%)\end{array}$ & ND & Zero \\
\hline & Huang (2020) ${ }^{20}$ & 41 & Shock $(7 \%)$ & $\begin{array}{l}\text { Elevated in } \\
12.2 \%\end{array}$ & $15 \%$ \\
\hline & Wang $(2020)^{2}$ & 118 & $\begin{array}{l}\text { Arrhythmia } \\
(16.7 \%) \text { Shock } \\
(8.7 \%) \text { Acute } \\
\text { cardiac injury } \\
(7.2 \%)\end{array}$ & Mean $6.4 \mathrm{pg} / \mathrm{ml}$ & $4.3 \%$ \\
\hline & Shi $(2020)^{1}$ & 416 & $\begin{array}{l}\text { Chest pain } \\
(3.4 \%) \\
\text { ST-depression } \\
\text { ECG }(0.7 \%)\end{array}$ & $\begin{array}{l}\text { Elevated in } \\
19.7 \%\end{array}$ & $13.7 \%$ \\
\hline
\end{tabular}




\begin{tabular}{|c|c|c|c|c|}
\hline $\begin{array}{l}\text { First author } \\
\text { (year) }\end{array}$ & $\begin{array}{l}\text { Number of } \\
\text { patients }\end{array}$ & $\begin{array}{l}\text { Cardiac } \\
\text { Manifestations }\end{array}$ & Troponin & $\begin{array}{l}\text { In-Hospital } \\
\text { Mortality }\end{array}$ \\
\hline Zhou $(2020)^{22}$ & 191 & $\begin{array}{l}\text { Heart Failure } \\
(23 \%) \\
\text { Hypotension } \\
(1 \%) \\
\text { HR> } 125 \mathrm{bpm} \\
(1 \%)\end{array}$ & Elevated in $17 \%$ & $28.2 \%$ \\
\hline Guo $(2020)^{21}$ & 187 & $\mathrm{VT} / \mathrm{VF}(5.9 \%)$ & $\begin{array}{l}\text { Elevated in } \\
27.8 \%\end{array}$ & $23 \%$ \\
\hline
\end{tabular}

Abbreviations: HF : heart failure; pt : patient;ND : not disclosed; RBBB : right bundle branch block;LVEF : left ventricular ejection fraction; TTE:transthoracic echocardiogram; CO : cardiac output; Rev : reversible; VT : ventricular tachycardia; SVT : supra ventricular tachycardia; HR : heart rate; VF : ventricular fibrillation.

Figure 1. Mechanisms and consequences of COVID-19 myocardial damage.

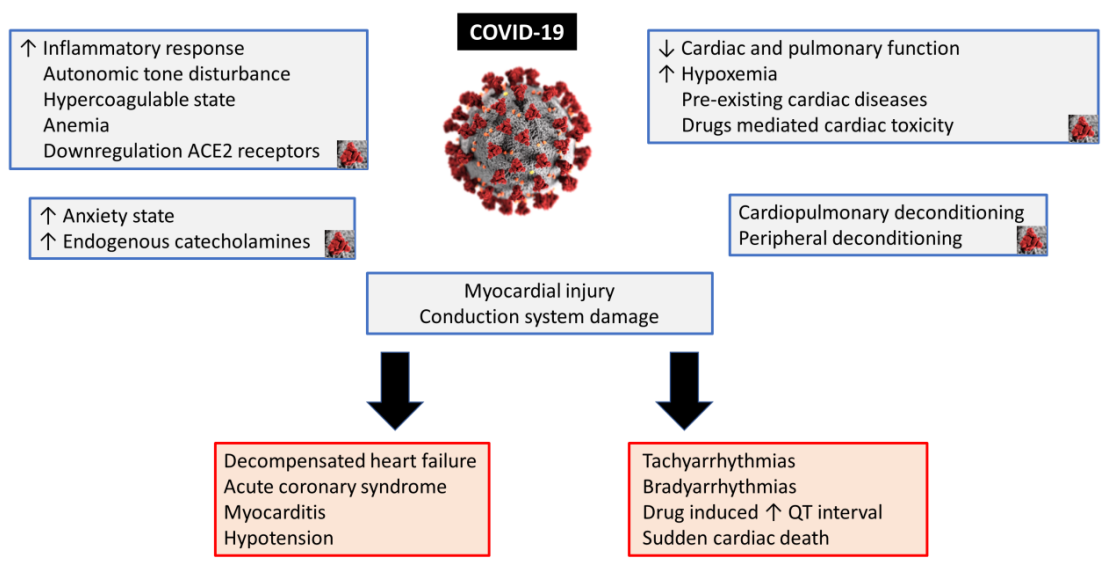

